\title{
Single-Atom Platinum Implanted on Manganese Dioxide Boosted High-Rate Performance of the Cathode for Zinc-Ion Battery
}

Zining Zhang, Song Li*, Xinyu Wang, Zhongsheng Wen and Juncai Sun Institute of Materials and Technology, Dalian Maritime University, Dalian 116026, China

\section{Corresponding Author}

* Song Li: lisong@dlmu.edu.cn

\section{Experimental Section}

\subsection{Fabrication of $\mathrm{Pt}-\mathrm{MnO}_{2}$, Pt (clusters) $-\mathrm{MnO}_{2}$ and $\mathrm{MnO}_{2}$}

The carbon cloth (named CC) $(6 \mathrm{~cm} \times 6 \mathrm{~cm} \times 1 \mathrm{~mm})$ was pretreated in $0.1 \mathrm{M}$ sulfuric acid solution for 12 hours and then rinsed with deionized water. Firstly, Pt$\mathrm{MnO}_{2} / \mathrm{CC}$ was synthesized by thermostatic electrochemical deposition. $500 \mathrm{~mL}$ $\mathrm{KMnO}_{4}(0.1 \mathrm{M}), 6 \mathrm{~mL} \mathrm{KOH}(1 \mathrm{M})$ and $2 \mathrm{~mL} \mathrm{H}_{2} \mathrm{PtCl}_{6}(500 \mu \mathrm{M})$ were prepared into electrolyte solution. Pt sheet $(6 \mathrm{~cm} \times 6 \mathrm{~cm} \times 0.05 \mathrm{~mm})$ was used as the cathode electrode and the carbon cloth was used as the anode electrode. The electrolyte solution was heated to $60{ }^{\circ} \mathrm{C}$ in a constant temperature water bath and magnetic stirring was carried out (300 r/min). Pt-MnO $2 / \mathrm{CC}$ was obtained by a potentiostat $(12 \mathrm{~V})$ which electroplated above solution for 120 minutes at constant temperature $\left(60{ }^{\circ} \mathrm{C}\right)$ and stirring speed $(100$ $\mathrm{r} / \mathrm{min}$ ). The carbon cloth was removed, rinsed with deionized water and dried at $100{ }^{\circ} \mathrm{C}$ for 5 hours. Secondly, Pt- $\mathrm{MnO}_{2}$ powder was obtained by machine stripping. The mass 
ratio of the powder and deionized water was 1:5. The mixture was introduced along with agate balls $(15 \mathrm{~mm}, 5 \mathrm{~mm}$ and $3 \mathrm{~mm})$ into an agate jar $(100 \mathrm{~mL})$ with a ball-topowder mass ratio of 8:1. We wet-ball milled the mixture (QM-QM 0.4) for 300 minutes at room temperature by $350 \mathrm{rpm}$. The target product $\mathrm{Pt}-\mathrm{MnO}_{2}$ was obtained after drying it at $100{ }^{\circ} \mathrm{C}$ for 5 hours. The preparation methods of Pt (clusters) $-\mathrm{MnO}_{2}$ and $\mathrm{Pt}-\mathrm{MnO}_{2}$ are the same, except that there is no magnetic stirring in the electrochemical deposition in $\mathrm{Pt}$ (clusters)- $\mathrm{MnO}_{2}$. In order to explain the role of singleatom $\mathrm{Pt}$, the synthesis of $\mathrm{MnO}_{2}$ was similar to that of $\mathrm{Pt}-\mathrm{MnO}_{2}$ except the addition for $\mathrm{H}_{2} \mathrm{PtCl}_{6}$.

\subsection{Material Characterization Apparatus}

The crystal structure of materials was analyzed by X-ray diffraction (XRD) applying the Rigaku-D/MAX-3A with $\mathrm{Cu}-\mathrm{K} \alpha$ radiation ( $\lambda=1.518 \AA$ ). The morphology of samples was characterized by field emission scanning electron microscope (FE-SEM, SUPRA 55 SAPPHIRE). STEM-EDX, TEM, HRTEM and HAADF-STEM mappings were utilized by FEI Titan G2 microscope with an aberration corrector for a probeforming lens and a Bruker Super-X spectrometer $(300 \mathrm{kV})$. The EXAFS analysis was tested by 1W1B station at the Beijing Synchrotron Radiation Facility (BSRF). X-ray photoelectron spectroscopy (XPS, K-Alpha 1063) was characterized the surface chemical composition. The specific surface area and pore distribution were measured using a ASAP2460. The content of single-atom Pt was determined by inductively coupled plasma optical emission spectrometry (ICP-OES). Raman spectrum is measured by INVIA (RENISHAW, U. K.) with the excitation wavelength of $532 \mathrm{~nm}$. 


\subsection{Electrochemical Measurements}

Pt- $\mathrm{MnO}_{2} / \mathrm{MnO}_{2}$ active substances (70 $\left.\mathrm{w} \mathrm{t} \%\right)$, acetylene black $(20 \mathrm{w} \mathrm{t} \%)$ and polyvinylidene fluoride binder $(10 \mathrm{w} \mathrm{t} \%)$ formed the test electrode. The mixture was ground with N-methyl pyrrolidinone and coated on a stainless-steel foil as a pole piece, followed by heating at $80^{\circ} \mathrm{C}$ in a vacuum oven overnight. $3 \mathrm{M} \mathrm{ZnSO}_{4}$ aqueous solution with $0.1 \mathrm{M} \mathrm{MnSO}_{4}$ additive is used as electrolyte. The CR 2025 coin-type cell was assembled with the above materials. GITT tests were performed by an electrochemical workstation (LAND, CT 2001 A) $(0.8-1.8 \mathrm{~V})$. EIS was examined based on an AC perturbation signal of $10 \mathrm{mV}(10 \mathrm{~m} \mathrm{~Hz}-100 \mathrm{k} \mathrm{Hz}) . \mathrm{CV}$ curves are obtained under various scan rates, i.e., $0.1-2 \mathrm{mV} \mathrm{s}^{-1}$.

\subsection{DFT calculations}

We performed first-principles density functional theory calculations using Perdew-Burke-Ernzerhof $(\mathrm{PBE})^{1}$ functional within the spin-polarized GGA+U approximation as implemented in the Cambridge serial total energy package $(\text { CASTEP })^{2}$ code. The Vanderbilt ultrasoft pseudopotential ${ }^{3}$ was used with a cutoff energy of $450 \mathrm{eV}$. Geometric convergence tolerances were set for the maximum force of $0.03 \mathrm{eV} / \AA$, maximum energy change of $10^{-5} \mathrm{eV} /$ atom, maximum displacement of $0.001 \AA$ and maximum stress of $0.5 \mathrm{G} \mathrm{Pa}$. Density mixing electronic minimization was implemented and the self-consistent field (SCF) tolerance was set to "fine" with high accuracy of $10^{-6} \mathrm{eV} /$ atom for energy convergence.

\section{HAADF-STEM image and STEM-EDS elemental mappings of Pt (clusters)- $\mathrm{MnO}_{2}$}


As depicted in Figure S1a, some platinum clusters are dispersed in the manganese dioxide structure. We analyzed a small platinum cluster by STEM-EDS elemental mappings and found that platinum elements were concentrated in the cluster which were consistent with our HAADF-STEM results (Figure S1b).

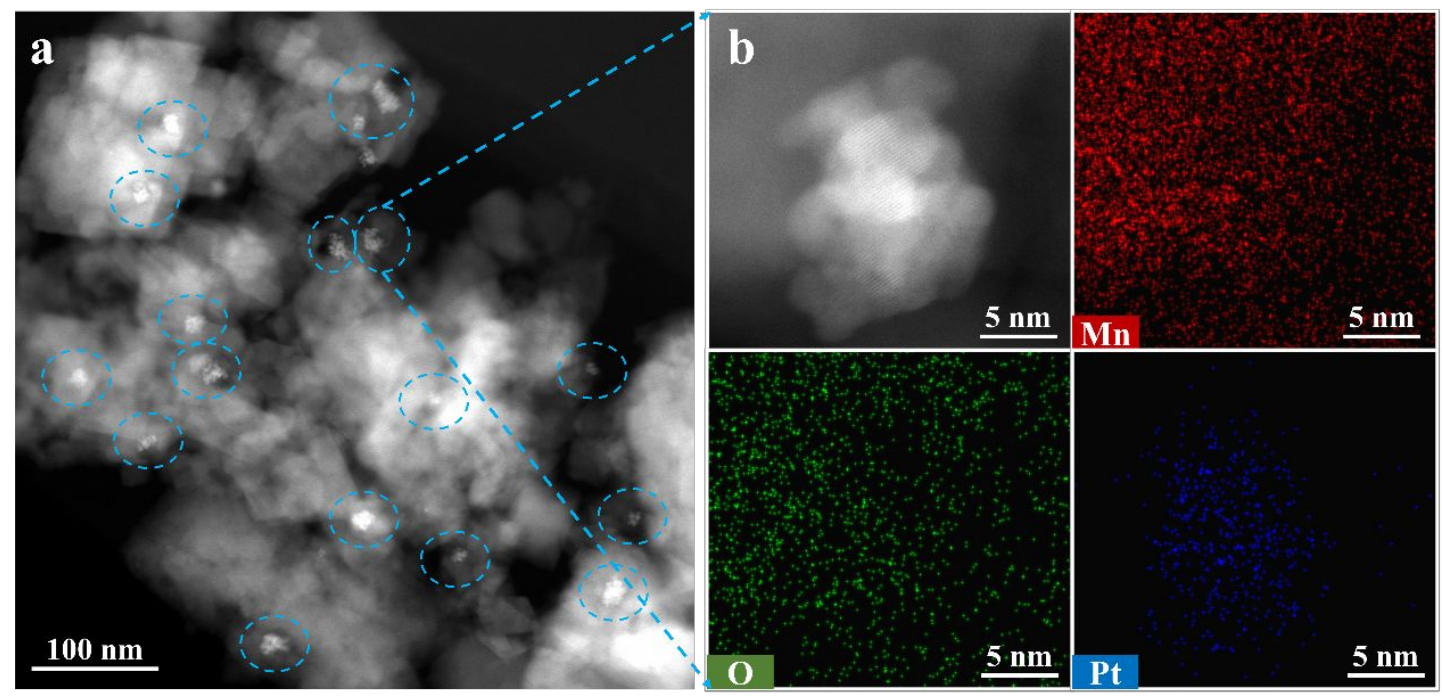

Figure S1. (a) HAADF-STEM image and (b) STEM-EDS elemental mappings of Pt (clusters)$\mathrm{MnO}_{2}$.

\section{Specific surface area and pore distribution of $\mathrm{Pt}-\mathrm{MnO}_{2}$ and $\mathrm{MnO}_{2}$}

The specific surface area of Pt- $\mathrm{MnO}_{2}$ and $\mathrm{MnO}_{2}$ is $53.29 \mathrm{~m}^{2} \mathrm{~g}^{-1}$ and $52.96 \mathrm{~m}^{2} \mathrm{~g}^{-1}$, respectively (Figure S2a). As illustrated in Figure S2b, the pore size distribution results show that there is a predominance of pores between 1.5 and $8 \mathrm{~nm}$ for $\mathrm{Pt}-\mathrm{MnO}_{2}$ and $\mathrm{MnO}_{2}$. The changes of specific surface area and pore size after single atom Pt doping $\mathrm{MnO}_{2}$ are almost negligible. 

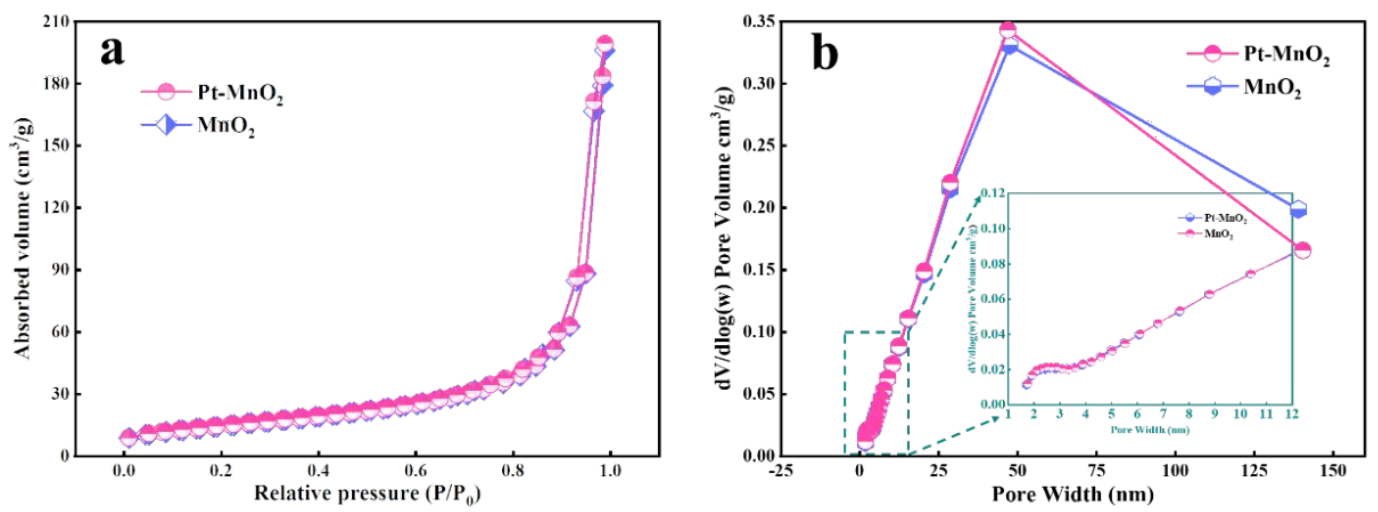

Figure S2. (a) Nitrogen adsorption-desorption isotherm and (b) pore distribution of Pt- $\mathrm{MnO}_{2}$ and $\mathrm{MnO}_{2}$.

\section{Roman spectrum of $\mathrm{Pt}-\mathrm{MnO}_{2}$ and $\mathrm{MnO}_{2}$}

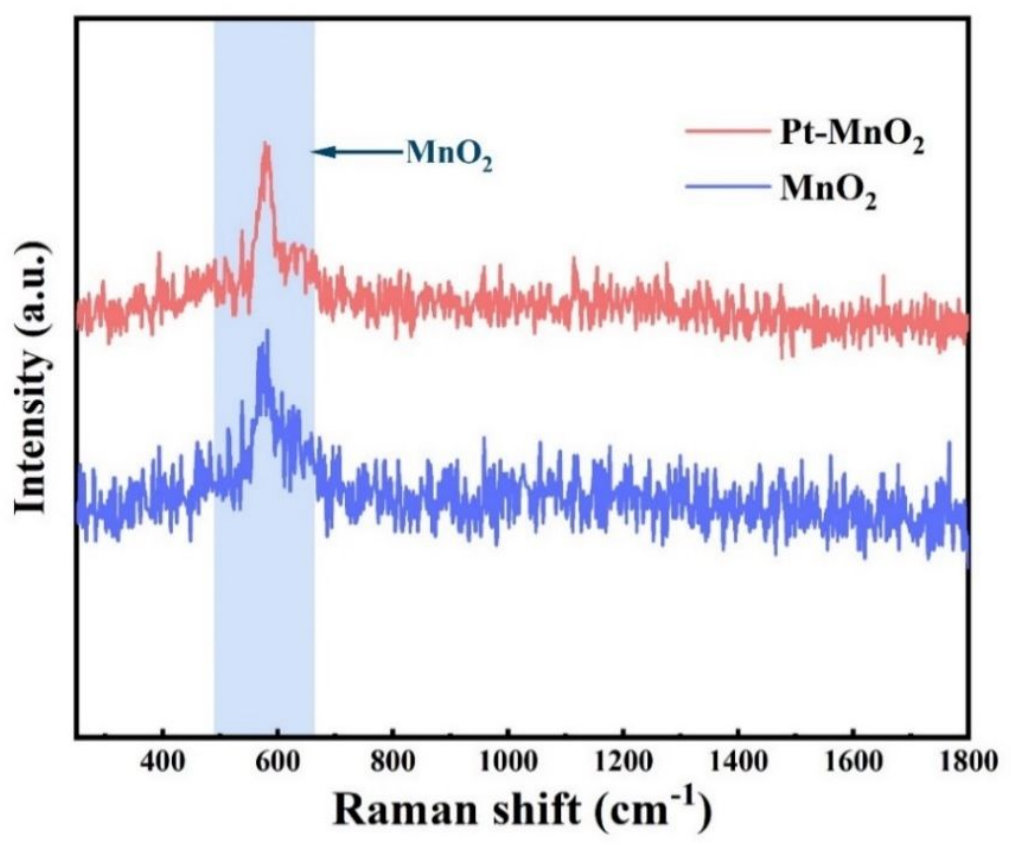

Figure S3. Roman spectrum of Pt- $\mathrm{MnO}_{2}$ and $\mathrm{MnO}_{2}$.

\section{ICP results of $\mathrm{Pt}-\mathrm{MnO}_{2}$ and $\mathrm{Pt}$ (clusters)- $\mathrm{MnO}_{2}$}




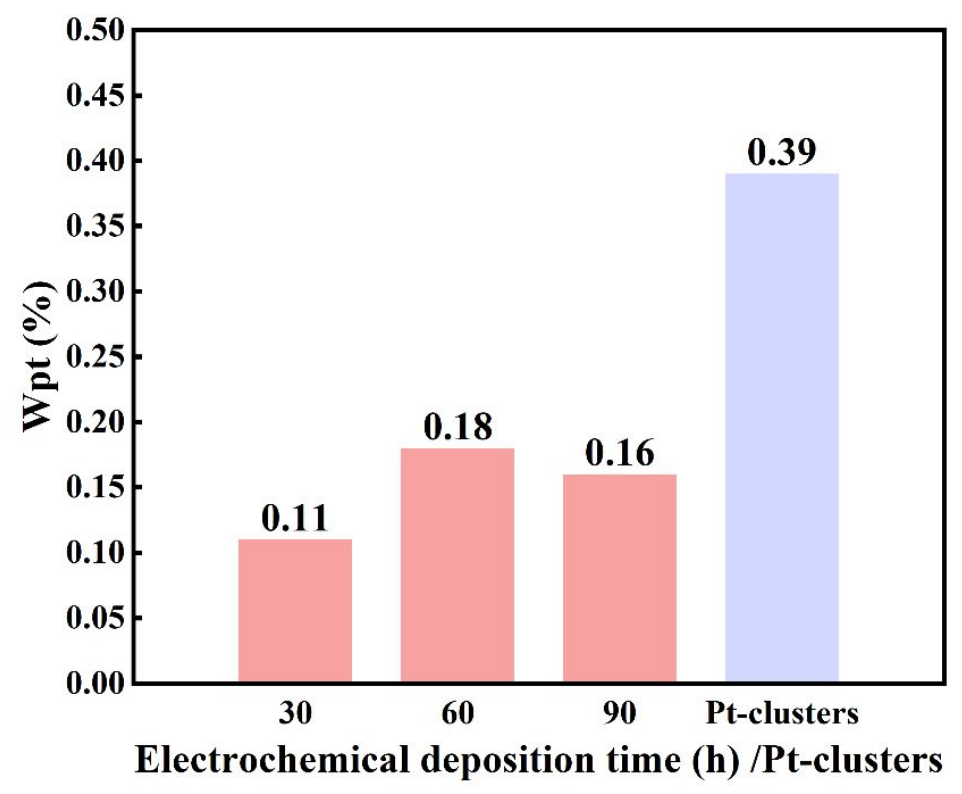

Figure S4. The percentage of single-atom Pt in ICP results of $\mathrm{Pt}-\mathrm{MnO}_{2}$ and $\mathrm{Pt}$ (clusters)- $\mathrm{MnO}_{2}$.

\section{Long-cycling performance of $\mathrm{Pt}-\mathrm{MnO}_{2}$ and $\mathrm{MnO}_{2}$}

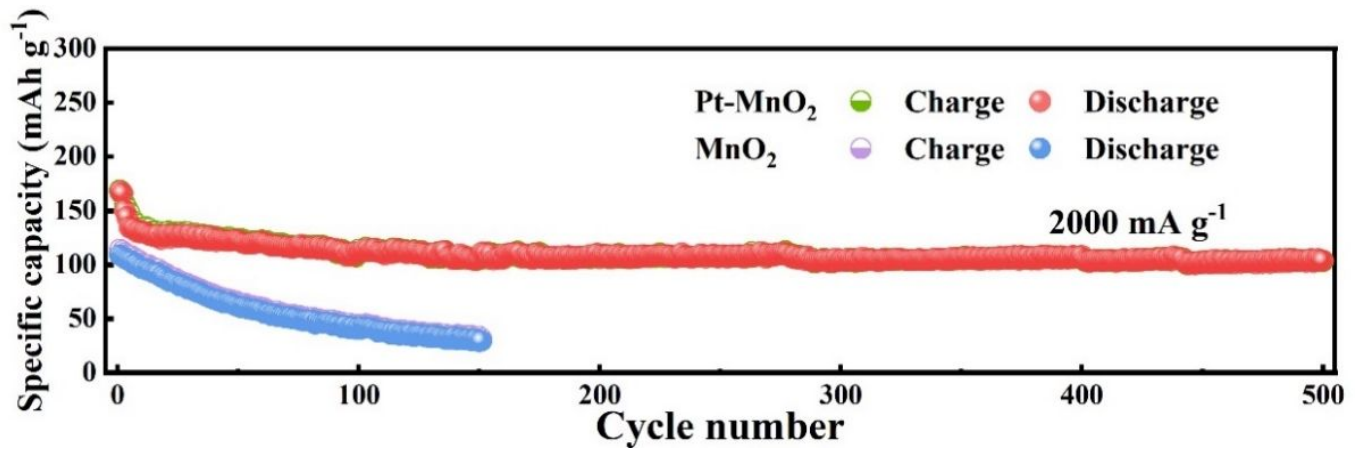

Figure S5. Long- cycling performance of $\mathrm{Pt}-\mathrm{MnO}_{2}$ and $\mathrm{MnO}_{2}$ at $2000 \mathrm{~mA} \mathrm{~g}^{-1}$.

\section{Rate performances of samples}




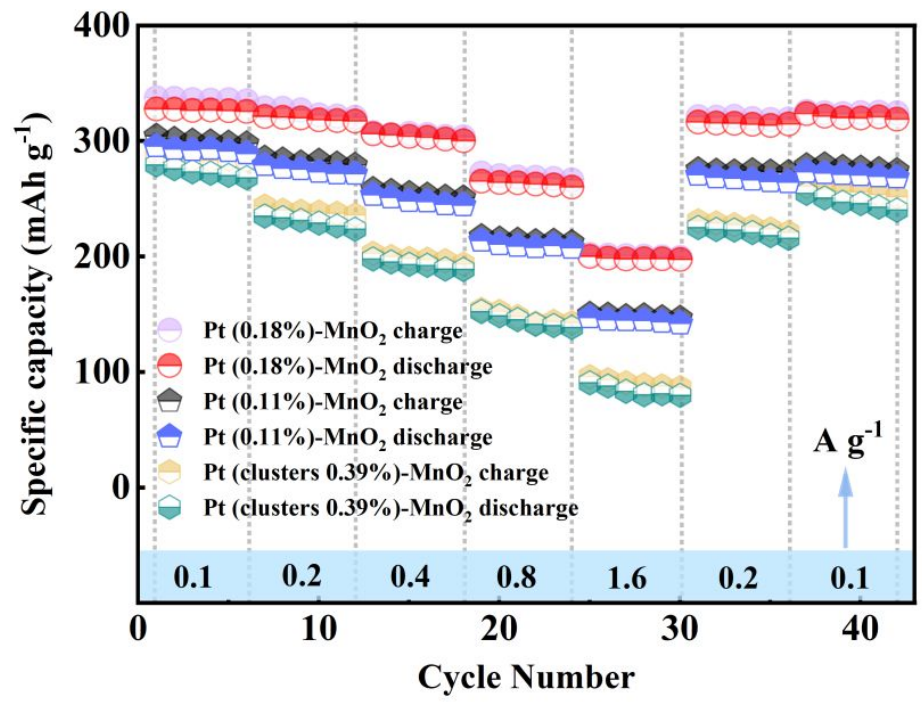

Figure S6. Rate performances of $\mathrm{Pt}(0.18 \%)-\mathrm{MnO}_{2}, \mathrm{Pt}(0.11 \%)-\mathrm{MnO}_{2}$ and $\mathrm{Pt}$ (clusters $\left.0.39 \%\right)$ $\mathrm{MnO}_{2}$

\section{8. $\mathrm{CV}$ curves of $\mathrm{MnO}_{2}$}

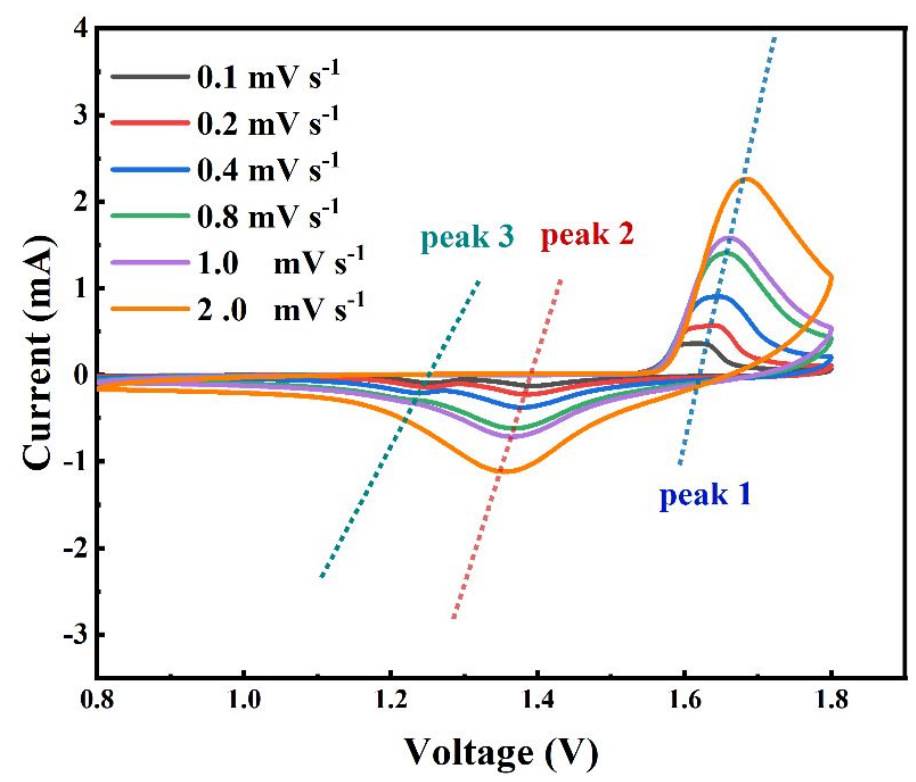

Figure S7. CV curves of $\mathrm{MnO}_{2}$ under various scan rates.

9. $\Delta$ values of $\mathrm{Pt}-\mathrm{MnO}_{2}$ and $\mathrm{MnO}_{2}$

\begin{tabular}{ccccccc}
\hline $\begin{array}{c}\text { Scan rate } \\
\left(\mathrm{mV} \mathrm{s}^{-1}\right)\end{array}$ & 0.1 & 0.2 & 0.4 & 0.8 & 1.0 & 2.0 \\
\hline $\begin{array}{c}\Delta(\mathrm{V}) \\
\mathrm{Pt}-\mathrm{MnO}_{2}\end{array}$ & 0.228 & 0.252 & 0.280 & 0.312 & 0.325 & 0.369 \\
\hline$\Delta(\mathrm{V})$ & 0.239 & 0.261 & 0.279 & 0.331 & 0.342 & 0.370 \\
\hline
\end{tabular}




\section{$\mathrm{MnO}_{2}$}

Note: $\Delta$ represents the distance between the oxidation peak (peak1) and the reduction peak (peak2).

Table S1. $\Delta$ values of Pt- $\mathrm{MnO}_{2}$ and $\mathrm{MnO}_{2}$.

\section{The calculation process of GITT}

The galvanostatic intermittent titration technique (GITT) was used for investigating the thermodynamic voltage-composition relationship and calculating the zinc-ion diffusion coefficients. In GITT calculation, a cell was charged or discharged at $200 \mathrm{~mA} \mathrm{~g}^{-1}$ rate for $20 \mathrm{~min}$, followed by a $1 \mathrm{~h}$ open circuit step to allow relaxation back to equilibrium (defined as $\mathrm{dE} / \mathrm{dt}<0.2 \mathrm{mV} \mathrm{h}^{-1}$ ). The procedure was continued until the charge/discharge voltage reached $1.8 \mathrm{~V}(0.8 \mathrm{~V})$. The ion diffusion coefficients could be calculated using the following equation first outlined by Weppner and Huggins: ${ }^{4}$

$$
D=\frac{4}{\pi}\left(I \frac{V_{m}}{Z_{A F S}}\right)^{2}\left(\frac{d E / d \delta}{d E / d \sqrt{\mathrm{t}}}\right)^{2}
$$

"I" represents the current (A); Vm is the molar volume of the NEG $\left(\mathrm{cm}^{3} \mathrm{~mol}^{-1}\right)$; $\mathrm{ZA}$ is the charge number; $\mathrm{F}$ is the Faraday's constant $\left(96485 \mathrm{C} \mathrm{mol}^{-1}\right)$; $\mathrm{S}$ is the electrode/electrolyte contact area $\left(\mathrm{cm}^{2}\right) ; \mathrm{dE} / \mathrm{d} \delta$ is the slope of the coulometric titration curve, found by plotting the steady state voltages E (V) measured after each titration step $\delta ; \mathrm{dE} / \mathrm{d} \sqrt{t}$ is the slope of the linearized plot of the potential $\mathrm{E}(\mathrm{V})$ during the current pulse of duration t (s). If sufficiently small currents are applied for short time intervals, so that $\mathrm{dE} / \mathrm{d} \sqrt{t}$ can be considered linear and the coulometric titration curve can be also considered linear over the composition range involved in that step, the above equation can be simplified into: ${ }^{5}$

$$
D=\frac{4}{\pi^{\tau}}\left(\frac{\mathrm{n}_{\mathrm{m}} V_{\mathrm{m}}}{S}\right)^{2}\left(\frac{\Delta E_{\mathrm{s}}}{\Delta E_{\tau}}\right)^{2}
$$

$\tau$ is the duration of the current pulse (s); $\mathrm{nm}$ is the number of moles (mol); $\mathrm{Vm}$ is the molar volume of the electrode $\left(\mathrm{cm}^{3} \mathrm{~mol}^{-1}\right)$; $\mathrm{S}$ is the electrode/electrolyte contact area $\left(\mathrm{cm}^{2}\right) ; \Delta E s$ is the steady-state voltage change, due to the current pulse and $\Delta \mathrm{Et}$ is the voltage change during the constant current pulse, eliminating the iR drop. 


\section{References}

1. Perdew, J. P.; Burke, K.;Ernzerhof, M. Generalized Gradient Approximation Made Simple. Phys. Rev. Lett. 1996, 77 (5), 3865-3868.

2. Segall, M. D.; Lindan, P. J. D.; Probert, M. J.; Pickard, C. J.; Hasnip, P. J.; Clark, S. J.;Payne, M. C. First-Principles Simulation: Ideas, Illustrations and the Castep Code. J. PhysCondens. Mat. 2002, 14 (6), 2717-2744.

3. Vanderbilt, D. Soft Self-Consistent Pseudopotentials in a Generalized Eigenvalue Formalism. Phys. Rev. B Condens Matter. 1990, 41 (11), 7892-7895.

4. Yan, M.; Mai, L.; He, P.; Chen, Y.; Shanyu Wang; Wei, Q.; Zhao, K.; Xu, X.; An, Q.; Shuang, Y. et al. Water Lubricated Intercalation in $\mathrm{V}_{2} \mathrm{O}_{5} \cdot \mathrm{nH}_{2} \mathrm{O}$ for High Capacity and High Rate Aqueous Rechargeable Zinc Batteries. Adv. Mater. 2018, 30 (1), 1703725-1703739.

5. Xia, C.; Guo, J.; Lei, Y.; Liang, H.; Zhao, C.;Alshareef, H. N. Rechargeable Aqueous ZincIon Battery Based on Porous Framework Zinc Pyrovanadate Intercalation Cathode. Adv. Mater. 2018, $30(5), 1705580-1705587$. 